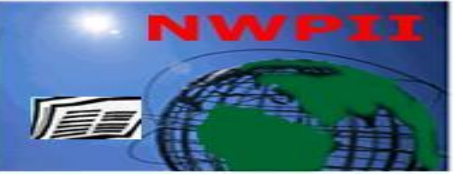

American Journal of Biomedical Sciences

ISSN: 1937-9080

nwpii.com/ajbms

\title{
A Comparative Study of Clinical and Environmental Isolates of Pseudomonas aeruginosa in Terms of Quorum Sensing, Outer Membrane Proteins and Their Ability to Cause Urinary Tract Infection
}

\author{
Ravi Kumar, Sanjay Chhibber, Kusum Harjai*
}

Dept. of Microbiology, BMS Block, Panjab University, Chandigarh, India- 160014

*Corresponding Author:

Dr. Kusum Harjai,

Department of Microbiology,

Basic Medical Sciences Block,

Panjab University,

Chandigarh,

India- 160014.

Ph. $+91-172-2534142$

Fax. +91-172-2541770

E mail: kusum_harjai@hotmail.com

Received: 25 January 2009; | Revised: 1April 2009; | Accepted: 26 April 2009

\begin{abstract}
Pseudomonas aeruginosa, one of the most common causes of nosocomial urinary tract infections, is widely distributed in environments. Environmental and clinical isolates have been compared on the basis of production of virulence factors and genomic diversity. However, no studies are available regarding the comparison of their physiological and morphological characteristics. 15 clinical and environmental isolates of Pseudomonas aeruginosa were screened for quorum sensing molecules and all were found to be producers of varied levels of acyl homoserine lactones (AHL's). Both the isolates showed comparable biofilm forming ability but revealed different outer membrane protein profile. Clinical isolate was found to be more virulent than environmental isolate on the basis of urine and renal colonization in experimental urinary tract infection mouse model. Histopathology and other pathology index factors like myeloperoxidase (MPO), malondialdehyde (MDA) and reactive nitrogen intermediate (RNI) level were also found to be more in case of animals infected with clinical isolates. In conclusion, despite similar abilities of biofilm formation and production of quorum sensing signal molecules, clinical isolate was found to have selective advantage in establishing and causing pathology in the urinary tract of mice. Our results indicate that pathogenicity potential of Pseudomonas aeruginosa vary depending on the source of strain as well as its outer membrane protein profile.
\end{abstract}

Keywords: Pseudomonas aeruginosa; Quorum sensing; Biofilm; Clinical and Environmental isolates; outer membrane proteins; Urinary tract infection. 


\section{Introduction}

Pseudomonas aeruginosa is epitome of opportunistic gram negative pathogen and has been listed as third most common organism causing $35 \%$ of catheter associated urinary tract infections (UTIs) (1). In many patients undergoing long term indwelling catheterization, infection of the urinary tract becomes inevitable (2). This organism has a tendency to form micro colonies on the catheter surfaces which coalesce together to form biofilms. Biofilms are resistant to antimicrobial agents as well as to host defense mechanisms leading to persistent infections which are difficult to eradicate. Due to these reasons, this pathogen is of major concern for treating clinicians.

The commonest source of $P$. aeruginosa causing hospital acquired UTIs is the environment where it is widely distributed in soil, water, sewage, plants and animal surfaces. The ability of $P$. aeruginosa to colonize and thrive in diverse environments is reflected by its relatively large genome size and genetic complexity. Large number of genes encoding outer membrane proteins, resistance - nodulation - cell division, efflux systems and multiple complex chemotaxis systems may contribute to its pathogenicity (3).

The crucial criterion which remains to be evaluated is the potential in vivo pathogenicity of $P$. aeruginosa from environmental sources since it is an opportunistic pathogen. Pathogenesis of $P$. aeruginosa is mutifactorial involving both cellular and extracellular factors. Lately production of quorum sensing signals by $P$. aeruginosa is also being assigned as the virulence property $(4,5)$. Like many other bacteria, $P$. aeruginosa uses chemical signals called quorum sensing signals to monitor their physiology and control the expression of virulence factors (6). Most of these signal molecules are acyl homoserine lactone (AHL's or autoinducers) which diffuses in and out of bacterial cells and regulate gene expression of cellular and extracellular virulence factors (7). Two such quorum sensing systems have been recognized in $P$. aeruginosa, the Las system and Rhl system (6). The role of quorum sensing in $P$. aeruginosa virulence has only begun to be studied. These signals have been reported to play important role in pathogenesis of burn wound, keratitis and respiratory tract infections induced by $P$. aeruginosa. This has been proven by in vivo studies using different animal models $(8,9,10)$ where demonstration of association of $P$. aeruginosa virulence with quorum sensing mechanisms has been done by comparing the virulence of $P$. aeruginosa mutants that carried deletions within quorum sensing (QS) genes with that of their parent strains.

On the other hand, it has also been reported that naturally occurring quorum sensing deficient strains of $P$. aeruginosa do occur in the environment as well as amongst clinical isolates from patients with urinary tract, lower respiratory tract and burn wound infections. Although these strains have been shown to form weak to moderate biofilms on abiotic surfaces but are capable of causing infections in humans (11). Since these pathogens are subsequently transmitted from the environment, this warrants the need to compare the environmental and clinical isolates. In this study, we have evaluated the clinical isolates and the isolates from the natural environment on the basis of quorum sensing signal production and outer membrane protein (OMP) profiles and further we have also tried to correlate these properties with establishment of urinary tract infection in mice.

\section{Materials and Methods}

Bacterial strains: 15 clinical isolates of Pseudomonas aeruginosa were obtained from urine samples collected from catheterized patients attending Govt. Medical College and Hospital, Chandigarh, India over a period of one year. 15 environmental isolates were also obtained from the water samples collected from the different water environment such as ponds and rivers. All the isolates were identified biochemically as Pseudomonas aeruginosa according to the Bergeys Manual of Determinative Bacteriology. The isolates were stored in $20 \%$ glycerol luria broth (LB) at $-80^{\circ} \mathrm{C}$. These stock cultures were used to inoculate LB broth every time to avoid repeated sub culturing of the isolates.

Cross feeding assay for AHL detection: LB agar plates covered with 40ul of X-gal (5- bromo - 
4- chloro -3- indoyl - $\beta$-D- galactopyranoside, $20 \mathrm{mg} / \mathrm{ml}$ stock solution in dimethyl formamide) was used for the cross feeding assay. E. coli MG4, used as reporter strain was streaked on the plate and then the culture to be tested was streaked approximately $1 \mathrm{~cm}$ apart. AHL's produced within the culture, diffused through the agar and resulted in activation of the tra $\mathrm{I}-$ lac $\mathrm{Z}$ fusion in the reporter strain. This assay was also used for detection of AHL's in urine and kidney tissue samples.

Autoinducer (AHL) measurement: For extraction of autoinducers from liquid cultures, bacterial isolates were grown in LB medium. Overnight culture was centrifuged and supernatant was separated. Supernatant was extracted with ethyl acetate containing $0.01 \%$ acetic acid twice according to the method of Bonte et al. (12). Quantitative determination of quorum sensing signals was then carried out using method of Zhu et al. (10). Each bioassay tube containing $2 \mathrm{ml}$ of reporter strain and $0.5 \mathrm{ml}$ of extracted supernatant of the test strain was incubated at $30^{\circ} \mathrm{C}$ in a water bath for $5 \mathrm{hr}$ with rotation at $100 \mathrm{rpm}$. $\beta$ galactosidase activity was then measured according to the method of Pesci et al. (13). Briefly, culture was centrifuged at $6000 \mathrm{rpm}$ for 15 minutes. Pellet was suspended in equal volume of $\mathrm{Z}$ buffer. To $1 \mathrm{ml}$ of cell culture, $1 \mathrm{ml}$ of $\mathrm{Z}$ buffer $\left(\mathrm{Z} \quad\right.$ Buffer- $\mathrm{Na}_{2} \mathrm{HPO}_{4} .7 \mathrm{H}_{2} \mathrm{O}-0.06 \mathrm{M}$, $\mathrm{NaH}_{2} \mathrm{PO}_{4} \cdot \mathrm{H}_{2} \mathrm{O}-0.04 \mathrm{M}$, KCL-0.01M, $\mathrm{MgSO}_{4} .7 \mathrm{H}_{2} \mathrm{O}-0.001 \mathrm{M}, \beta$-mercaptoethanol-0.05M, $\mathrm{pH}-7.0)$ was added. Bacterial cells were then lysed by adding $200 \mu \mathrm{l}$ chloroform and $100 \mu \mathrm{l}$ of $0.1 \%$ SDS. Vortexed for $30 \mathrm{sec}$ 's followed by addition of $0.4 \mathrm{ml}$ of $\mathrm{O}$-nitrophenol- $\beta$-D-galactopyranoside (ONPG, $4 \mathrm{mg} / \mathrm{ml}$ in PBS) and incubated in $30^{\circ} \mathrm{C}$ water bath. Reaction was stopped by adding $1 \mathrm{ml}$ of $1 \mathrm{M} \mathrm{Na} \mathrm{Co}_{3}$ after the development of yellow color. OD was taken at $420 \mathrm{~nm}$ and OD at $550 \mathrm{~nm}$ of the reaction samples. Units of $\beta$-galactosidase were calculated as $=1000 \times \mathrm{A} 420-(1.75 \times \mathrm{A}$ 550) /Time x volume x A 600

Outer membrane protein profiling: Outer membrane proteins of all isolates were prepared according to the standard method of Bolin and Jansen. (14). Briefly, single colony was inoculated in $100 \mathrm{ml}$ of TSB and incubated at $37^{\circ} \mathrm{C}$ under shaking conditions. Cells were collected by centrifuging over night culture. Cells were sonicated by $30 \mathrm{~s}$ pulse sonication for $5 \mathrm{~min}$. Resultant mixture was centrifuged at $10,000 \mathrm{rpm}$ for $10 \mathrm{~min}$. and $10 \mathrm{ml}$ of supernatant was incubated at room temperature for $30 \mathrm{~min}$. with $1 \mathrm{ml}$ of $1 \%$ $\mathrm{N}$-lauryl sarcosine. It was centrifuged at $1,10,000$ $\mathrm{rpm}$ for $1 \mathrm{~h}$ at $4^{0} \mathrm{C}$. Pellet was washed with $20 \mathrm{mM}$ Tris buffer and ultracentrifugation was repeated. Pellet was dissolved in minimum amount of 20 $\mathrm{mM}$ Tris buffer. OMP profiling was done by using $5 \%$ stacking and $10 \%$ resolving gel. SDS-PAGE electrophoresis was carried out according to the method of Laemmli (15).

Biofilm generation assay: Sterile Foley's catheter piece of $1 \mathrm{~cm}$ were cut from the tubing (Rusch ) and biofilm was allowed to develop under stationary conditions for 7 days by regularly changing the catheter piece to fresh medium after every $24 \mathrm{hrs}$. Each day catheter pieces in duplicate were removed and were placed in separate vials, rinsed thrice with phosphate buffer saline (PBS $\mathrm{pH}$ 7.2) and sliced longitudinally into equal halves. Cells were removed from the surface of catheter pieces by scrapping the surface with sterile scalpel blade. Cells were sonicated by low level sonication cycle and then vortexed for 30 seconds. Dispersed sample was then centrifuged and the biofilm cells were suspended in $1 \mathrm{ml}$ PBS. Serial dilutions were then made, plated on nutrient agar plates and incubated at $37^{\circ} \mathrm{C}$ for 24 hours.

\section{Induction of acute ascending} pyelonephritis: Method of Hagberg et al. (16) was used for the induction of urinary tract infection. For the use of animals, ethics approval was granted by Panjab University Ethics Committee. Female LACA (Swiss Webster) mice, 6-8 weeks old, free of bacteriuria were used for the experiment. $50 \mathrm{ul}$ of $10^{8} \mathrm{cfu} / \mathrm{ml}$ of adjusted inoculum was introduced into the bladder of mice using a soft non- radio-opaque polyethylene tubing (outer diameter $0.61 \mathrm{~mm}$, Clay Adams, USA). Urine and kidneys were collected aseptically.

Bacteriological examination: Animals were sacrificed on $3^{\text {rd }}$ and $5^{\text {th }}$ post infection day. Aseptically removed kidneys were weighed and homogenized in $1 \mathrm{ml}$ sterile saline solution. Quantitative bacterial counts were calculated per 
gram of kidney tissue as reported by Kakkar et al. (17).

Histopathological examination: Kidneys were fixed in $10 \%$ buffered normal saline and dehydrated in 30-100\% gradient ethanol. Paraffin wax blocks were prepared and $5 \mathrm{u}$ thin sections were stained with hematoxylin and eosin. Medulla, cortex, calyx and subcalyx of each kidney were evaluated.

Malondialdehyde (MDA) estimation: Induction of pathology was evaluated on the basis of MDA, the index of lipid peroxidation in renal tissue. Method of Anjaneyulu and Chopra (18) was employed. Briefly, $0.5 \mathrm{ml}$ of the tissue homogenate was added to $0.5 \mathrm{ml}$ of Tris $\mathrm{HCl}(0.1$ $\mathrm{M}, \mathrm{pH7.4)}$ and incubated at $37^{\circ} \mathrm{C}$ for 2 hours followed by addition of $1 \mathrm{ml}$ of ice-cold Trichloroacetic acid $(10 \% \mathrm{w} / \mathrm{v})$. Samples were centrifuged at $1000 \mathrm{rpm}$ for 10 minutes. $1 \mathrm{ml}$ of supernatant was taken and mixed with $1 \mathrm{ml}$ of thiobarbituric acid $(0.67 \% \mathrm{w} / \mathrm{v})$. Tubes were covered and kept in boiling water bath for 10 minutes. After cooling, absorbance was read at $532 \mathrm{~nm}$.

Myeloperoxidase assay (MPO): Tissue neutrophils were quantitated by using the myeloperoxidase (MPO) assay by the method of Hang et al. (19). Briefly, tissues were homogenized in $2 \mathrm{ml}$ of $50 \mathrm{mM}$ potassium phosphate $\mathrm{pH} 6.0$ with $0.5 \%$ hexadecyl trimethyl ammonium bromide and $5 \mathrm{mM}$ EDTA. The homogenate was sonicated and centrifuged at $12,000 \mathrm{~g}$ for 15 minutes. Supernatant was then mixed with 1:15 assay buffer (O-diansidine $0.167 \mathrm{mg} . \mathrm{ml}$ in $50 \mathrm{mM}$ phosphate buffer with $5 \mathrm{ul}$ of $\mathrm{H}_{2} \mathrm{O}_{2}$ ) and absorbance was read at $490 \mathrm{~nm}$.

Assay for reactive nitrogen intermediates (RNI): Nitrite was estimated in renal tissues of infected mice following method of Rockett et al., (20). Briefly, $100 \mu \mathrm{l}$ of sample was mixed with $200 \mu \mathrm{l}$ of Griess reagent (Sigma Chemicals, USA) followed by addition of $100 \mu \mathrm{l}$ of $10 \%$ trichloroacetic acid and incubated for 20 minutes at room temperature. After centrifugation, optical density of supernatants was read at $540 \mathrm{~nm}$. The amount of nitrite was determined using standard curves of sodium nitrite.

Statistical analysis: All the experiments were repeated three times to validate the reproducibility of experiments. Results were analyzed statistically by Student's $t$ test using Sigmastat software to calculate $p$ values.

\section{Results and discussion}

P. aeruginosa is a ubiquitous environmental bacterium that is capable of infecting a wide variety of animals and plants. Source of infection still remains to be environment. Few studies are available where workers have compared the environmental and clinical isolates with respect to production of certain virulence factors $(21,22)$. These strains have also been compared on the basis of genomic diversity (22). However, it is not clear whether there is an intrinsic difference in physiological and morphological characteristics of both these strains which may contribute towards the in vivo pathogenicity of an organism. Production of known virulence factors by Pseudomonas aeruginosa was done previously in our lab (23). This study was planned to investigate the incidence of quorum sensing signals, biofilm formation and OMP profiles of $P$. aeruginosa strains isolated from clinical samples and those existing in the environment and to further check their potential to cause urinary tract infection in experimental model. For the detection and measurement of autoinducers, E. coli MG4 was used as a reporter strain in cross feeding assay and for estimation of $\beta$ - galactosidase activity. This reporter strain carries Lac $\mathrm{Z}$ gene fusion in its genome which resulted in the appearance of blue coloration of reporter strain in presence of autoinducers produced by the test strain. All clinical and environmental isolates were found to be positive for the production of autoinducers however their levels varied as assessed by $\beta$ galactosidase assay. Although clinical isolates showed higher $\beta$ - galactosidase activity (98.4 MU) as compared to environmental isolates where activity was low (96.7 MU) but the difference was not found to be statistically significant (data not shown). These results indicated that quorum sensing is the inherent property of $P$. aeruginosa whether these strains exist in the environment or in a clinical setting. 


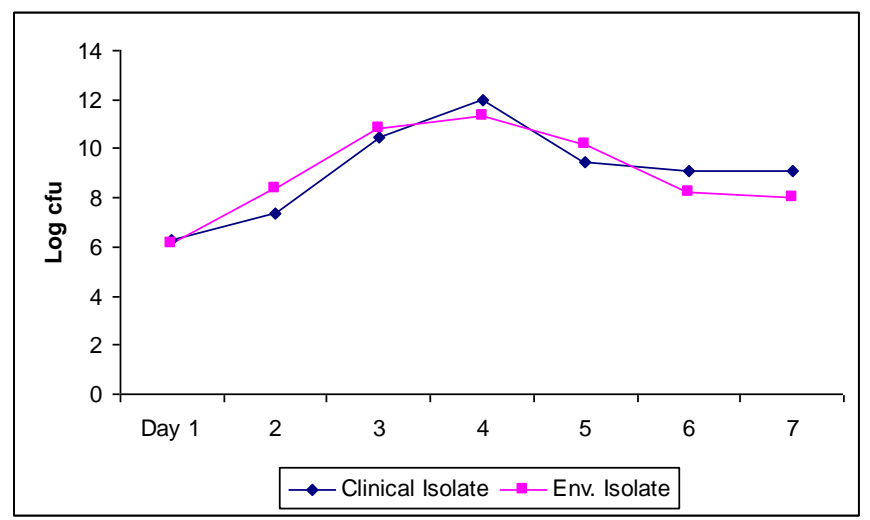

Figure 1: Comparison of biofilm forming ability on catheter surfaces by clinical and environmental isolate of Pseudomonas aeruginosa.

Both clinical and environmental isolates were able to form biofilms on catheter surface implying that biofilm formation might convey a selective advantage to these pathogens by increasing their ability to persist under diverse environment of the nature as well as that of the host (24). The environmental isolate formed almost comparable biofilm as indicated by estimation of log $\mathrm{cfu}$ (Figure 1). Increase in log cfu was observed upto $4^{\text {th }}$ day with slow decline after wards. Dispersal of cells from biofilm communities is a common phenomenon (25). Late stage biofilms exceeding the thickness of a monolayer is known to develop in 4 days after which biofilm dispersion can take place naturally or can be induced (26). Loss of cells in the form of decreased log counts of biofilm cells is not restricted to the last stage of biofilm development $(26,27)$ but may occur continuously at low levels over the course of biofilm formation. Decrease in log count observed after $4^{\text {th }}$ day may be due to release of cells from the biofilm into the medium (cell dispersion) or cell lysis. Killing and lysis within the $P$. aeruginosa biofilms were also observed by Webb et al. (25) after $3^{\text {rd }}$ and $7^{\text {th }}$ day of biofilm formation. These workers proposed prophage mediated cell death which play important role in subsequent biofilm differentiation and dispersal. Simultaneous decrease in $\beta$-galactosidase activity with decrease in log cfu was observed in the present study in both environmental and clinical isolates (data not shown) indicating that biofilm development is regulated by quorum sensing mechanism.

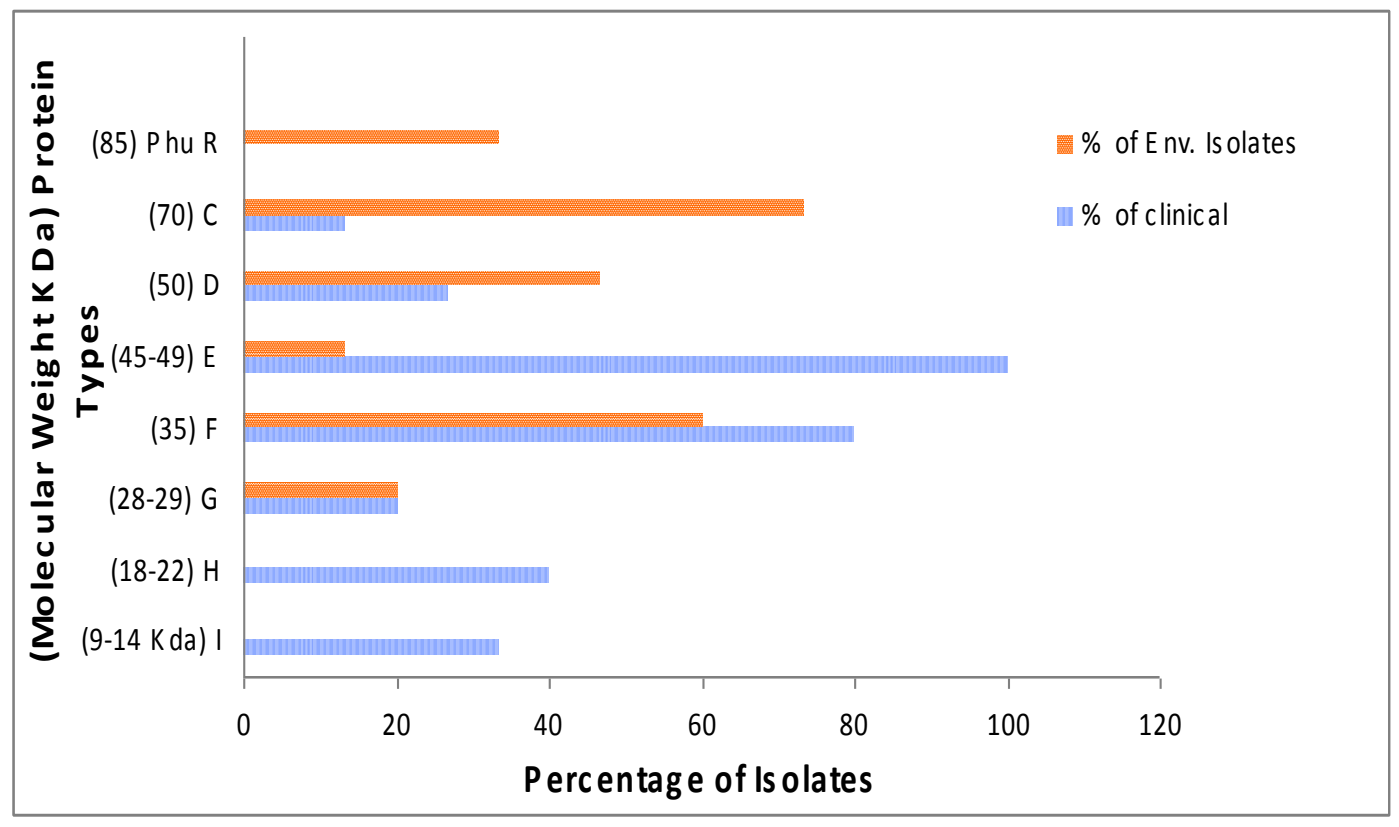

Figure 2: Percentage distribution and types of outer membrane proteins observed among clinical and environmental isolates of Pseudomonas aeruginosa.

The outer membrane of $P$. aeruginosa has significant importance in its establishment in the environment as well as in living host since they constitute the cellular layer which is in direct 
contact with the environment. We thereafter went on to study the omp profiles of these isolates. Distinct type of outer membrane proteins were observed in clinical and environmental isolates. Majority of clinical isolates showed protein type $\mathrm{E}$ (45-49 KDa) and F (35 KDa). Both of these proteins have been functionally related to the porin proteins, efflux system and adhesion (27). Since ability to adhere and resistance to antimicrobial agents are important properties which an organism must possess for survival and later establishment of disease in vivo conditions, these properties may significantly contribute towards establishment of clinical isolate of $P$. aeruginosa in the experimental host. Few isolates also showed the lipoproteins I, H, G and D which have important functions in efflux system. Majority of environmental isolates showed presence of proteins like PhuR, C and D which are shown to be related to iron and copper uptake with glucose inducible, properties important for survival in natural environment (Figure 2). No similarity in the protein pattern of clinical and environmental isolates as well as within the clinical and environmental isolates was observed. Considerable variation in omp types with strains isolated from different sources was observed by Maloney et al. Similar results were observed by Stobberingh et al. (28) in an epidemiological study while comparing different phenotypic methods for the typing of $P$. aeruginosa isolated from various sources. However, Hancock and Chan. (29) reported close similarity between clinical and environmental isolates on the basis of outer membrane protein profiling. A number of studies have also found differences with respect to production of virulence factors as well as genetic differences among clinical and environmental isolates including the genome region controlling the virulence genes (21). However, it is not clear whether there is an intrinsic difference in their ability to cause urinary tract infection.

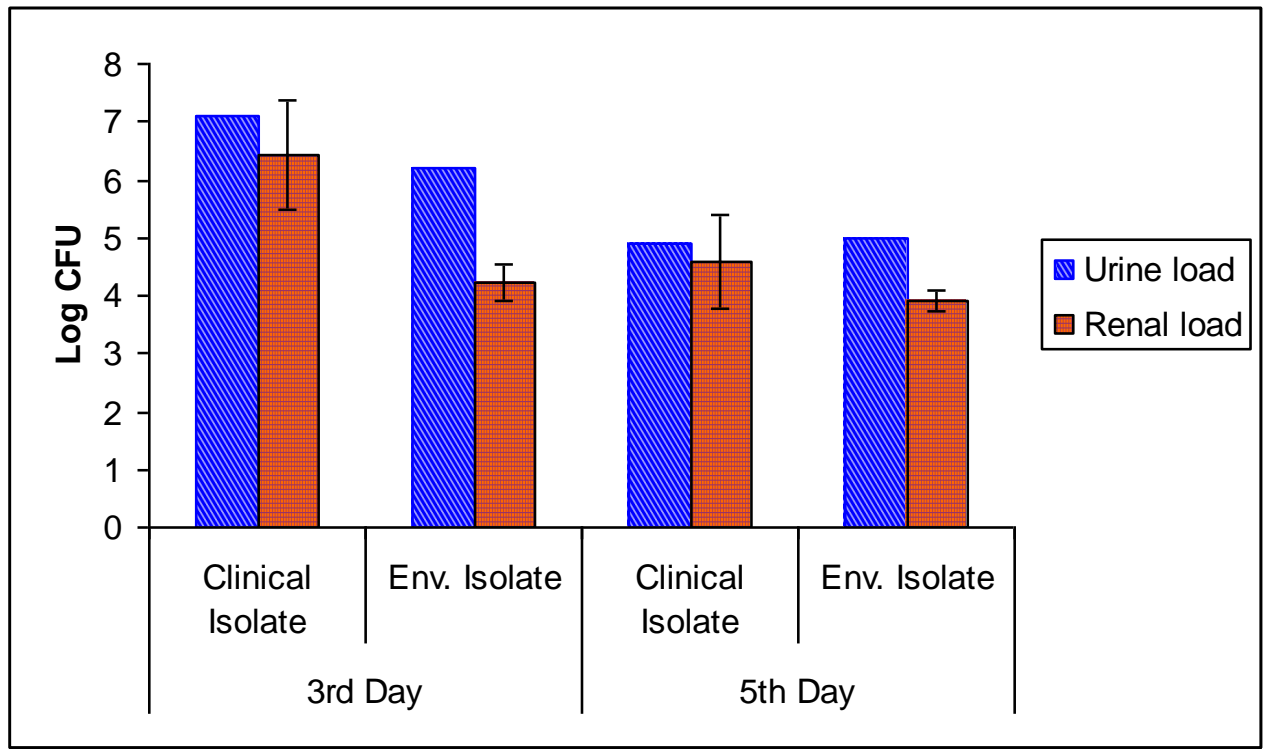

Figure 3. Comparative bacterial load of urine and renal tissue of mice infected with clinical and environmental isolate of $P$. aeruginosa. Values represent the average counts of 16 animals in each group \pm standard deviation with $p \leq 0.001$ (CI vs EI on $3^{\text {rd }}$ day) and $p \leq 0.02$ (CI vs EI on $5^{\text {th }}$ day).

To study this, virulence potential of both the isolates was checked in experimental model of UTI. Level of establishment of UTI was assessed on the basis of urine and renal bacterial load with pathology index factors including histopathological lesions and level of MPO, MDA and RNI in renal tissue. In case of mice infected with environmental isolate, bacterial lodgment in kidney tissue was significantly less $(\mathrm{p} \leq 0.001, \mathrm{p} \leq$ 0.02 ) on both $3^{\text {rd }}$ and $5^{\text {th }}$ post infection days as compared to clinical isolate (Figure 3). Production of QS molecules were also detected on $3^{\text {rd }}$ and $5^{\text {th }}$ day in the urine and renal tissue of experimental mice indicating the importance of quorum sensing 
signals in the pathogenesis of urinary tract infections. Histopathological lesions in renal tissue of mice were found to be in accordance with the results of bacterial lodgment. Clinical isolate showed more tissue destruction as compared to the environmental isolate. In mice, infected with clinical isolate, kidney tissue sections showed severe inflammation in the interstitium of medullary and cortical region, along with Infilteration of neutrophils in the glomeruli and sub epithelium of renal pelvis (Figure 4). On the other hand mice infected with environmental isolate showed mild to moderate inflammation with mild neutrophil infiltration in the kidney tissue (Figure 5). Infilteration of neutrophils in renal tissue of mice was also assessed by estimating myeloperoxidase enzyme (MPO) secreted by neutrophils, monocytes and some macrophages. MPO level was found to be more in mice infected with clinical isolate on both post infection days but it was not statistically significant indicating that despite similar infilteretion of neutrophils in both the groups, clinical isolate was able to survive their phagocytic action better than the environmental isolate. Severity of disease was also detected by the estimation of products produced during the killing of the invading pathogens by the participating cells. MDA level of mice infected with clinical isolates were significantly more as compared to mice infected with environmental isolates $(p \leq 0.03)$. Similarly mice infected with clinical isolates showed significantly more reactive nitrogen intermediate units in kidney tissue of mice as compared to mice infected with environmental isolate on both post infection days $(p \leq 0.003, p \leq 0.03$ ) (Table 1).

Contradictory reports exist in literature regarding similarity of environmental and clinical isolates. Janda and co-workers (30) reported that environmental isolates may differ from clinical isolates in their ability to produce elastase, the major protease of $P$. aeruginosa which is known to contribute to in vivo virulence and exo $\mathrm{S}$ which is important for survival in soil (30). Different in vitro biofilm forming capacities and reduced ability of lung colonization was observed in environmental isolates as compared to clinical isolates by Head and $\mathrm{Yu}$ (22). However Woods et al. (31) were not able to differentiate both the isolates on the basis of correlation of production of extracellular enzymes and LD50.

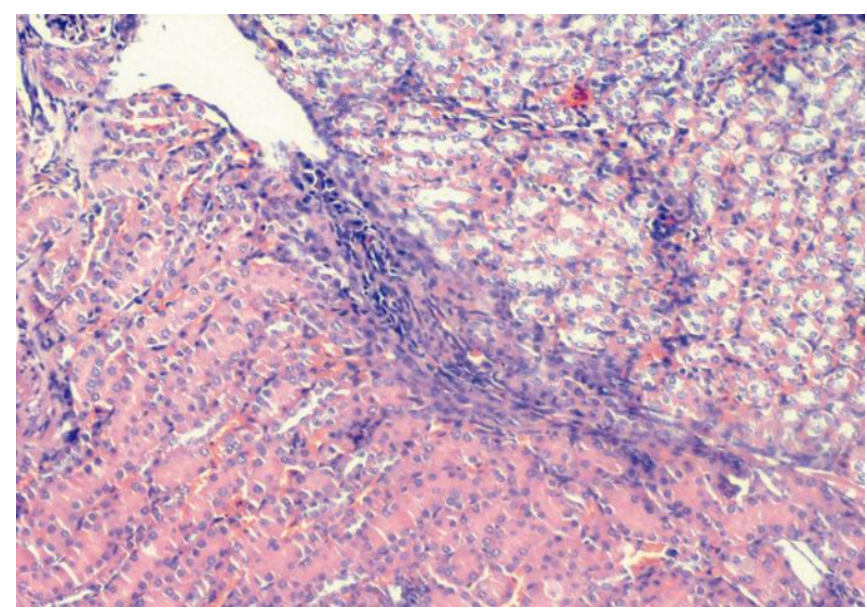

Figure 4: Photomicrograph showing severe inflammation in medulla region of kidney tissue infected with clinical isolate of Pseudomonas aeruginosa (HandE x 200).

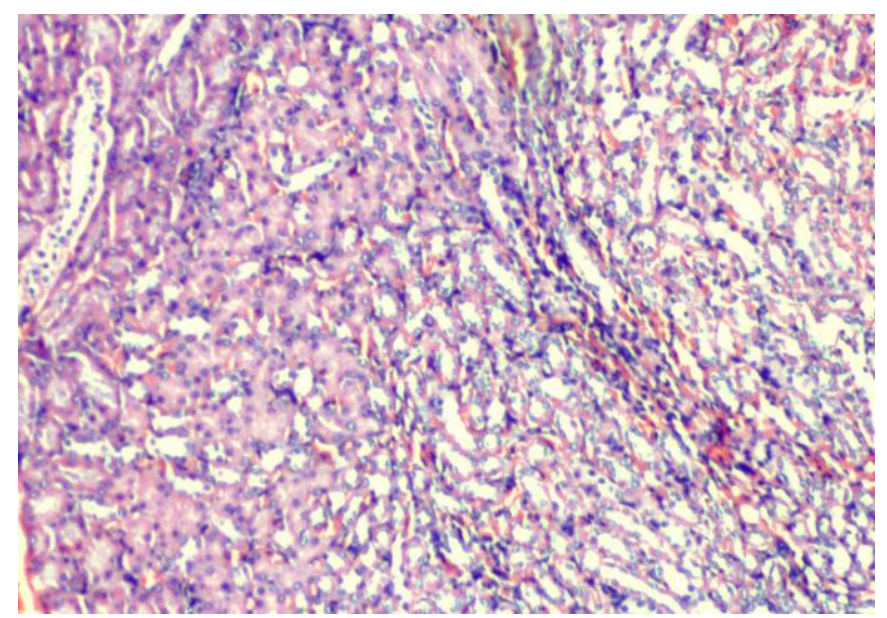

Figure 5: Photomicrograph showing mild inflammation in medulla region of kidney tissue infected with environmental isolate of Pseudomonas aeruginosa (HandE x 200).

In this study, we have observed that environmental isolates differ from clinical isolates with respect to their outer membrane protein profiles and their ability to establish in the urinary tract of mouse. Environmental isolate although produced comparable amounts of AHL's and biofilms in vitro but were found to be less virulent in the experimental urinary tract infection model 
as compared to clinical isolate. This indicate that clinical isolate might be having some selective advantage in terms of relevant outer membrane proteins required for growth and establishment in the hostile environment of the host. On the other hand environmental isolate with different outer membrane protein profile may need more time to adapt to such environment. Thus we conclude that although pathogenic potential is a general property of $P$. aeruginosa from all sources but intensity may vary depending on the basis of origin of strains and their outer membrane protein profiles.

Table 1: Level of other pathology index factors like MPO, MDA and RNI estimations in renal tissue homogenates of mice infected with clinical and environmental isolate of $P$. aeruginosa.

\begin{tabular}{|c|c|c|c|c|c|c|}
\hline \multirow{2}{*}{$\begin{array}{l}\text { Day of } \\
\text { Sacrifice }\end{array}$} & \multicolumn{2}{|c|}{ MPO units } & \multicolumn{2}{|c|}{ MDA level } & \multicolumn{2}{|c|}{ RNI units } \\
\hline & $\mathrm{CI}^{*}$ & $E I^{* *}$ & $\mathrm{CI}$ & EI & $\mathrm{CI}$ & EI \\
\hline 3rd day & $0.162 \pm 0.02$ & $0.155 \pm 0.02$ & $1.72 \pm 0.41$ & $1.29 \pm 0.17$ & $202.1 \pm 36.9$ & $123 \pm 43.7$ \\
\hline 5th day & $0.161 \pm 0.02$ & $0.142 \pm 0.02$ & $1.9 \pm 0.30$ & $1.68 \pm 0.23$ & $214.8 \pm 70.4$ & $136.2 \pm 53.4$ \\
\hline$p$ values & : (3 $3^{\text {rd }}$ day $)$ & $p \geq 0.06$ & $p \leq$ & .03 & $p \leq 0$. & 003 \\
\hline$(* \mathrm{vs} * *$ & ) (5 $5^{\text {th }}$ day): & $p \geq 0.09$ & $p \geq$ & 13 & $p \leq$ & 0.03 \\
\hline
\end{tabular}

\section{Acknowledgement:}

We acknowledge the Indian Council of Medical Research, New Delhi, India for providing contingency grant for this project work.

\section{References}

1). Jarvis, W.R.; Martone, W.J. Predominant pathogens in hospital infections, $\mathrm{J}$ Antimicrob Chemother, 1992, 29, 19-24.

2). Kunin, C. Detection, prevention and management of urinary tract infections, Lea and Febiger, Philadelphia, 1987.

4). Givskov, M.; Hentzer, M.; Riedel, K.; Rasmussen T.B.; Eberl, L.; Hoiby, N. Inhibition of quorum sensing in Pseudomonas aeruginosa biofilm bacteria by a halogenated furanone compound, Microbiol, 2002, 148, 87102.

5). Juhas, M.; Eberl, L.; Tummler, B. Quorum sensing: the power of cooperation in the world of Pseudomonas, Environ Microbiol, 2005, 7, 459-471.

6). Pearson, J.P.; Feldman, M.; Iglewski, B.H.; Prince, A. Pseudomonas aeruginosa cell-tocell signaling is required for virulence in a model of acute pulmonary infection, Infect Immun, 2000, 68(7), 4331-4334.

7). Williams, S.C.; Patterson, E.K.; Carty, N.L.; Griswold, J.A.; Hamood, A.N.; Rumbaugh, K.P. Pseudomonas aeruginosa autoinducer enters and functions in mammalian cells, J Bacteriol, 2004, 186 (8), 2281-2287. 
8). Tang, J.L.; Feng, J.X.; He, Y.Q.; Findlay, K.; Crossman, L.; Dow, J.M. Biofilm dispersal in Xanthomonas campestris is controlled by cell -cell signaling and is required for full virulence to plants, Proc Natl Acad Sci, 2003, 100, 10995-11000.

9). Rumbagh, K.P.; Griswold, J.A.; Iglewski, B.H.; Hamood, A.N. Contribution of quorum sensing to the virulence of Pseudomonas aeruginosa in burn wound infections, Infect Immun, 1999, 5854-5862.

10). Zhu, H.; Bandara, R.; Conibear, T.C.; Thuruthyil, S.J.; Rice, S.A.; Kjelleberg, S.; Givskov, M.; Willcox, M.D. Pseudomonas aeruginosa with lasI quorum-sensing deficiency during corneal infection, Invest Ophthalmol Vis Sci, 2004, 45(6), 1897-1903.

11). Shaber, J.A.; Carty, N.L.; Mcdonald, N.A.; Graham, E.D.; Griswold, J.A.; Hamood, A.N. Analysis of quorum sensing deficient clinical isolates of Pseudomonas aeruginosa, J Med Microbio, 2004, 53, 841-853.

12). Bonte, S.F.; Kohler, T.; Delden, C.V. Biofilm formation by Pseudomonas aeruginosa: role of the C4- HSL cell to cell signal and inhibition by azithromycin, J Antimicobial Chemo, 2003, 52, 598-604.

13). Pesci, E.C.; Milbank, J.B.; Pearson, J.P.; McKnight, S.; Kende, A.S.; Greenberg, E.P.; Iglewski, B.H. Quinolone signaling in the cellto-cell communication system of Pseudomonas aeruginosa, Proc Natl Acad Sci, 1999, 96(20), 11229-11234.

14). Bolin, C.A.; Jensen, A.E. Passive immunization with antibodies gainst iron regulated outer membrane proteins protects turkeys from E. Coli septicemia, Infect Immun, 1987, 1239-1242.

15). Laemmli, U.K. Cleavage of structural proteins during the assembly of the head of bacteriophage T4, Nature, 1970, 227, 680685.

16). Hagberg, L.; Enberg, I.; Feter, R.; Lam, j.; Olling, S.; Svanberg, E.S. Ascending unobstructed urinary tract infection in mice caused by pyelonephritogenic E. coli of human origin, Infect Immun, 1983, 40, 273-283.

17). Kakkar, K.; Sharma, S.; Asnani, P.J.; Banerjee, C.K.; Sharma, B.K. Experimental haemategenous pyelonephritis in mice with uropathogenic, enteropathogenic and enterotoxigenic E. coli, Antonie Van Leewen, 1986, 52, 153-161.

18). Anjaneyulu, M.; Chopra, K. Effect of irbesartan on the antioxidant defence system and nitric oxide release in diabetic rat kidney, Am J Nephr, 2004, 24, 488-496.

19). Hang, L.; Haraoka, M.; Agace, W.W.; Leffler, H.; Burdick, M.; Strieter, R.; Svanborg, C. Macrophage inflammatory protein-2 is required for neutrophil passage across the epithelial barrier of the infected urinary tract, J Immunol, 1999, 162, 30373044.

20). Rockett, K.A.; Awburn, M.M.; Rockett, E.J.; Cowden, W.B.; Clark, I.A. Possible role of nitric oxide in malarial immunosuppression, Parasite Immunol, 1994, 16 (5), 243-249.

21). Finnan, S.; Morrissey, J.P.; Gara, F.O.; Boyd, E.F. Genomie diversity of Pseudomonas aeruginosa isolates from cystic fibrosis pateints and the hospital environemnt, J Clin Mirobiol, 2004, 5783-5792.

22). Head, N.E.; Yu, H. Cross sectional analysis of clinical and environmental isolates of Pseudomonas aeruginosa: biofilm formation, virulence and genetic diversity, Infect Immune, 2004, 133-144.

23).Mittal, R.; Khandwaha, R. K.; Gupta, V.; Mittal, P. K.; Harjai, K. Phenotypic characters of urinary isolates of Pseudomonas aeruginosa and their association with mouse renal colonization, Ind J Med Res, 2006, 123, 67-72.

24). Stoodley, L.H.; Stoodley, P. Biofilm formation and dispersal and the transmission of human pathogens, Trends Microbiol, 2005, 13, 7-10.

25). Webb, J.S.; Thompson, L.S.; James, S.; Charlton, T.; Nielsen, T.T.; Koch, B. Cell death in Pseudomonas aeruginosa biofilm development, 2003, 4585-4592.

26). Sauer, K.; Cullen, M.C.; Rickard, A.H.; Zeef, L.A.H.; Davies, D.G.; Gilbert, P. Characterization of nutrient induced dispersion in Pseudomonas aeruginosa PA01 biofilm, J Bacteriol, 2004, 7312-7326.

27). Riedel, K.; Givskov, M.; Kjellberg, S.; Gorg, A.; Reil, G.; Eberl, L. Identification of quorum

(c) 2009 by NWPII. All rights reserved. 
sensing regulated proteins in the opportunistic pathogen Pseudomonas aeruginosa by proteomics, Env Microbiol, 2003, 5, 13501369.

28). Stobberingh, E.; Bergmans, D.; Bonten, M.; Tiel, F.V.; London, N.; Leeuw, P.D. Value of phenotyping methods as an initial screening of Pseudomonas aeruginosa in epidemiological studies, Infection, 1997, 6, 350-354.

29). Hancock, R.E.W.; Chan, L. Outer membrane of environmental isolates of Pseudomonas aeruginosa, J Clin Microbiol, 1988, 24232424.
30). Janda, K.D.; Dickerson, T.J.; Brogan, A.P.; Clapham, B.; Moss, J.A.; Kaufmann, G.F. Revisiting quorum sensing: discovery of additional chemical and biological functions for 3- oxo - N - acylhomoserine lactones, Proc Natl Aca Sci, 2005, 102, 309-314.

31). Woods, D.E.; Lam, J.S.; Parenchych, W.; Speet, D.P.; Campbell, M.; Godfrey, A.J. Correlation of virulence factors from clinical and environmental isolates with pathogenicity in the neutropenic mouse model, Can J Microbiol, 1997, 43, 541-551. 